\title{
Clinical Significance of Plasma Diamine Oxidase Activity in Pediatric Patients: Influence of Nutritional Therapy and Chemotherapy
}

\author{
YOSHIAKI TANAKA, HIROYOSHI MIZOTE, TAKAHIRO ASAKAWA, HIDEFUMI KOBAYASHI, \\ MARI OTANI, KEN TANIKAWA, HIROTAKA NAKAMIZO, CHIAKI KAWAGUCHI, \\ KIMIO ASAGIRI, KENJIRO AKIYOSHI, SHIGEKI HIKIDA \\ AND TSUYOSHI NAKAMURA*
}

Department of Pediatric Surgery, Kurume University School of Medicine, Kurume 830-0011 and *EN Otsuka Pharmaceutical Co., Ltd, Japan

\begin{abstract}
Summary: The aims of this study were to determine the normal values of plasma diamine oxidase (pDAO) activity in children and to examine the influence of several factors (nutritional management, dietary fiber, and chemotherapy) on pDAO activity. The activity of pDAO was measured in 138 healthy children with minor surgical conditions such as inguinal hernia or undescended testis. In order to define normal values patients were subdivided into 5 groups according to age. Next, changes in pDAO activity under different nutritional conditions were studied in 14 patients with adhesive ileus. The influence of chemotherapeutic drugs on pDAO activity was also studied in 19 neuroblastoma patients. I. The normal values of pDAO activity at year $<1,1 \leqq$ years $<3,3 \leqq$ years $<$ $6,6 \leqq$ years $<12,12 \leqq$ years were $6.65 \pm 1.75,7.70 \pm 2.29,6.53 \pm 1.68,5.85 \pm 1.87,5.06 \pm 1.84$ units/l, respectively. II. The pDAO activities in patients with ileus were $4.73 \pm 1.02$ (total parenteral nutrition), $6.84 \pm 1.18$ (enteral nutrition), $7.62 \pm 0.67$ (soluble dietary fiber added enteral nutrition) and $8.82 \pm 1.26$ units/l (oral feeding). The difference in pDAO activity at enteral or oral feeding vs. total parenteral nutrition was significant $(p<.0001)$. III. The pDAO activity decreased significantly and remained low during the first 4 days after cyclophosphamide administration in neuroblastoma patients. The preadministration of dietary fiber inhibited the influence of cyclophosphamide. Plasma DAO activity was greatly influenced by nutritional management and administration of dietary fiber and/or cyclophosphamide. Plasma DAO activity may be a sensitive marker of intestinal function in children.
\end{abstract}

Key words amine oxidase, intestinal mucosa, enteral nutrition, dietary fiber, chemotherapy

\section{INTRODUCTION}

Diamine oxidase is the major enzyme of polyamine degradation [1] and its activity rises in parallel with that of ornithine decarboxylase (ODC) during adaptive intestinal hyperplasia [2]. It is localized in tissues with rapid cell-turnover such as intestine and placenta, specifically villi tips of mammalian enterocytes in humans [3], and is released from its capillary binding sites in the lamina propria of villi tips into the peripheral circulation and then inactivated in the liver [4]. Luk noted that plasma diamine oxidase (pDAO) activity rose in parallel with intestinal pDAO levels in maturing rats [5], while it progres-

Received for publication November 10, 2003

Correspondence to: Yoshiaki Tanaka, MD, Department of Pediatric Surgery, Kurume University School of Medicine, 67 Asahi-machi, Kurume 830-0011, Japan. Tel: +81-942-31-7631 Fax: +81-942-31-7705 E-mail:yoshi456@med.kurume-u.ac.jp

Abbreviations: av, average; CPM, cyclophosphamide; DA-67, 10-(carboxymethyl-amimocarbonyl)-3,4-bis(dimethylamino) phenothiazine sodium salt; DAO, Diamine oxidase; EN, enteral nutrition; m, month; MES, 2-( $N$-morpholino) ethanesulfonic acid monohydrate; ODC, ornithine decarboxylase; pDAO, Plasma diamine oxidase; PIPES, piperazine- $N, N^{\prime}$-bis(2-ethanesulfonic acid); PO, per oral nutrition; SDF, soluble dietary fiber; TPN, total parenteral nutrition; VCR, vincristine; yr, year. 
sively decreased with increasing length of intestinal mucosal injury in the adult rat [6]. These findings suggest that pDAO activity might be influenced by growth or intestinal stress (e.g. surgery, chemotherapy or nutritional management). Previous reports in children had only described pDAO activity associated with intractable diarrhea [7-9], until we reported the influences of liver dysfunction [10]. In addition, due to its low plasma activity level, most investigators injected heparin intravenously, which can release diamine oxidase into circulation from binding sites in the intestine. However, we used a highly sensitive colorimetry for measurement, and therefore we did not need a heparin load. As a result our method is safer for pediatric patients in the perioperative period or those having hemorrhagic diathesis.

In the present study we first determined the normal values of pDAO activity in healthy children who had no organic abnormalities other than inguinal hernia or undescended testis in each of five age groups, and then clinically examined the influences of several intestinal conditions (nutritional management, dietary fiber, and chemotherapeutic drugs) on the pDAO activity.

\section{MATERIALS AND METHODS}

I. The subjects were 138 healthy patients in our department aged 2 months (m)-19 years (yrs) $8 \mathrm{~m}$ (average (av.) 7 yrs $1 \mathrm{~m}$ ) who had no organic/functional abnormalities in the gastrointestinal tract or liver, and no disturbances of growth or development except for inguinal hernia or undescended testis. They were divided into 5 age groups and plasma DAO activities were measured to establish the normal values for each group: $(\mathrm{yr}<1 ; 2 \mathrm{~m}-11 \mathrm{~m}$ (av. $7 \mathrm{~m}) \mathrm{n}=10$, $1 \leqq \mathrm{yr}<3 ; 1$ yr-2 yrs $11 \mathrm{~m}$ (av. 1 yr $7 \mathrm{~m}) \mathrm{n}=52,3 \leqq$ yr $<6 ; 3$ yrs $2 \mathrm{~m}-5$ yrs $9 \mathrm{~m}$ (av. 4 yrs $7 \mathrm{~m}$ ) $\mathrm{n}=22,6 \leqq$ yr $<12 ; 6$ yr $1 \mathrm{~m}-11$ yrs $11 \mathrm{~m}$ (av. 8 yr $8 \mathrm{~m}$ ) $\mathrm{n}=30$, $12 \leqq$ yr; 12 yr $5 \mathrm{~m}-19$ yrs $8 \mathrm{~m}$ (av. 14 yr $6 \mathrm{~m}$ ) $\mathrm{n}=24$ ). For a control, the values of pDAO activity in adults aged 24 yrs $8 \mathrm{~m}-42$ yrs $4 \mathrm{~m}$ (av. 29 yr $7 \mathrm{~m}$ ) were measured $(n=20)$.

II. The changes in pDAO activity under different types of nutritional management were studied in 14 patients with postoperative adhesive ileus who had been not able to intake orally ( $2 \mathrm{~m}-5$ yrs $6 \mathrm{~m}$, av. 2 yrs $4 \mathrm{~m}$ ). That is to say, the changes in pDAO activity were studied during 5 courses; total parenteral nutrition (TPN) management, TPN \& enteral nutrition (EN) management, EN management, soluble dietary fiber added EN management, and oral feeding. The dose of the soluble dietary fiber (a partially hydrolyzed guar gum), Sunfiber (Taiyo Kagaku, Yokkaichi, Japan) under EN management was 0.5 $\mathrm{g} / \mathrm{kg} / \mathrm{day}$. The total energy given was $435 \pm 25$ $\mathrm{kJ} / \mathrm{kg} / \mathrm{day}(104 \pm 6 \mathrm{kcal} / \mathrm{kg} /$ day$)$ on average underunder each nutritional management system.

III. The influences of anticancer drugs on pDAO activity were also studied in 19 patients with neuroblastoma. Plasma DAO was measured in 9 patients with neuroblastoma Stage II ( $7 \mathrm{~m}-1$ yr $3 \mathrm{~m}$, av. $9.2 \mathrm{~m})$ in order to examine the influence of chemotherapy. Cyclophosphamide (CPM, $300 \mathrm{mg} / \mathrm{m}^{2}$ ) or vincristine (VCR, $1.5 \mathrm{mg} / \mathrm{m}^{2}$ ) was given and $\mathrm{pDAO}$ activities before and after the administration of each anticancer drug were measured. The time frame between these administrations was 1 week, and VCR was administrated first. Additionally, the influence of CPM administration was examined in 10 patients with neuroblastoma Stage IVA (av. $6 \mathrm{~m}-1$ yrs $5 \mathrm{~m}$, av. 8.9 $\mathrm{m})$. The dose of CPM $\left(600-1200 \mathrm{mg} /{ }^{2}\right)$ was $2-4$ times higher than in the Stage II cases. The patients were prepared with soluble dietary fiber $(1 \mathrm{~g} / \mathrm{kg} /$ day $)$ for 10 days prior to chemotherapy and this administration was continued for up to 2 weeks after completion of chemotherapy.

The parents of the children gave informed written consent to participate in the study, which was approved by the Ethics Committee of the Faculty of Medicine at Kurume University.

Plasma DAO activity was assayed according to the modified method of Takagi et al. [11], which was based on a coupled reaction with peroxidase and a chromogen, 10-(carboxymethyl-amimocarbonyl)-3,4bis (dimethylamino) phenothiazine sodium salt (DA67). First, $0.5 \mathrm{ml}$ of substrate solution $(30 \mathrm{mM}$ cadaverine in PIPES buffer at $\mathrm{pH} 7.2$ ) and $0.1 \mathrm{ml}$ of plasma were mixed. This mixture was incubated at $37^{\circ} \mathrm{C}$ for exactly $30 \mathrm{~min}$. Then, $0.5 \mathrm{ml}$ of color solution $(4.08 \mathrm{mg}$ of DA-67, 600 units of peroxidase and 500 units of ascorbate oxidase in $100 \mathrm{ml}$ of MES buffer at $\mathrm{pH}$ 5.4) was added and incubated further at $37{ }^{\circ} \mathrm{C}$. Immediately after incubation for $60 \mathrm{~min}, 0.025$ $\mathrm{ml}$ of stop solution $(0.513 \mathrm{mg}$ of sodium diethylditiocarbamate in $100 \mathrm{ml}$ of water) was added and mixed, and then the colorimetric adsorption was measured at $668 \mathrm{~nm}$. For a standard, $0.1 \mathrm{ml}$ of the DAO standard solutions $(0,0.625,1.25,2.5,5,10$ and 20 units of DAO in $1000 \mathrm{ml}$ of PIPES buffer at $\mathrm{pH} \mathrm{7.2)} \mathrm{were}$ used in place of plasma. DA-67, ascorbate oxidase, MES and PIPES were purchased from Wako (Osaka, Japan). Peroxidase, DAO, cadaverine and sodium diethylditiocarbamate were purchased from Sigma 
(St. Louis, MO, USA). Because it was possible to reduce the substrate solution to $0.5 \mathrm{ml}$, the sample concentration could be increased and the amount of coloring solution reduced. This method enabled us to measure activities lower than those of Takagi et al. (2.5-50 units/L vs. over 0.625 units/L). This method had other advantages over HPLC as well: simpler analytical operation, higher sensitivity, and safer measurement without heparin load for patients in the perioperative period or those with hemorrhagic diathesis.

The precision of the method was estimated by assaying 10 replicates of human serum samples. The coefficient variance was $3.8 \%$ (Mean $\pm \mathrm{SD}, 6.81 \pm$ 0.26 units/L).

\section{Statistical analysis}

The results were expressed in means $\pm S D$. Statistical analysis was performed with StatView 5.0 (SAS Institute, Cary, NC, USA). Differences between results obtained in the various age groups of our healthy population were evaluated making use of Mann-Whitney's U-test. Comparisons between results before/after chemotherapy and between each type of nutritional therapy were performed by the Wilcoxon matched pair test. (A level of significance $<5 \%$ was considered significant).

\section{RESULTS}

\section{Normal values of pDAO activity (Table 1)}

The average normal values of pDAO activity in the respective age groups were $6.65 \pm 1.75$ units/L in infancy, $7.70 \pm 2.29$ units/L in $1-3$ year olds, $6.53 \pm$ 1.68 units/L in 3-6 year olds, $5.85 \pm 1.87$ units/L in 612 year olds, and $5.06 \pm 1.84$ units/L in puberty. Plasma DAO activity increased through the 1-3 year old group and then gradually decreased to become analogous to the value in adults. The average pDAO activity of 1-3 year old patients was significantly higher than that of patients over 6 years old.

\section{Influence of nutritional therapy on pDAO activity (Table 2)}

Plasma DAO activity gradually increased during the course of nutritional therapy: $4.73 \pm 1.02$ units/L in TPN management, $5.46 \pm 1.48$ units/L in the transition period from TPN management to EN management, 6.84 1.18 units/L in EN management, 7.62 \pm 0.67 units/L in soluble dietary fiber added EN management, and $8.82 \pm 1.26$ units/L in oral feeding. Plasma DAO activity significantly recovered in EN management, or later, as compared with TPN management. Moreover, pDAO activity in the oral feeding period was significantly higher than that in the

TABLE 1.

Normal values of plasma diamine oxidase $(n=138)$

\begin{tabular}{|c|c|c|}
\hline Age (mean age $\&$ range) & $\begin{array}{l}\text { pDAO activity } \\
\text { (units/l) }\end{array}$ & $\begin{array}{c}P \text { value } \\
(\text { vs. } 1 \leqq \mathrm{y}<3)\end{array}$ \\
\hline $\begin{array}{l}\mathrm{yr}<1(2 \mathrm{~m}-11 \mathrm{~m} . \text { av. } 7 \mathrm{~m}) \\
(\mathrm{n}=10,6 \text { boys, } 4 \text { girls })\end{array}$ & $6.65 \pm 1.75$ & NS \\
\hline $\begin{array}{l}1 \leqq y r<3(1 \mathrm{yr}-2 \mathrm{yrs} 11 \mathrm{~m}, \text { av. } 1 \mathrm{yr} 7 \mathrm{~m}) \\
(\mathrm{n}=52,29 \text { boys }, 23 \text { girls })\end{array}$ & $7.70 \pm 2.29$ & - \\
\hline $\begin{array}{l}3 \leqq y r<6(3 \text { yrs } 2 \mathrm{~m}-5 \text { yrs } 9 \mathrm{~m}, \text { av. } 4 \text { yrs } 7 \mathrm{~m}) \\
(\mathrm{n}=22,12 \text { boys, } 10 \text { girls })\end{array}$ & $6.53 \pm 1.68$ & NS \\
\hline $\begin{array}{l}6 \leqq y r<12(6 \text { yrs } 1 \mathrm{~m}-11 \text { yrs } 11 \mathrm{~m}, \text { av. } 8 \text { yrs } 8 \mathrm{~m}) \\
(\mathrm{n}=30,14 \text { boys, } 16 \text { girls })\end{array}$ & $5.85 \pm 1.87$ & .0014 \\
\hline $\begin{array}{l}12 \leqq y r(12 \text { yrs } 5 \mathrm{~m}-19 \text { yrs } 8 \mathrm{~m} \text {, av. } 14 \text { yrs } 6 \mathrm{~m}) \\
(\mathrm{n}=24,11 \text { boys, } 13 \text { girls })\end{array}$ & $5.06 \pm 1.84$ & $<.0001$ \\
\hline $\begin{array}{l}\text { Adult }(24 \text { yrs } 8 \mathrm{~m}-42 \text { yrs } 4 \mathrm{~m} \text {, av. } 29 \text { yrs } 7 \mathrm{~m}) \\
(\mathrm{n}=20,12 \text { men, } 18 \text { women })\end{array}$ & $4.85 \pm 1.48$ & $<.0001$ \\
\hline
\end{tabular}

pDAO activity is expressed as the mean \pm SD. Statistical analysis was performed using the Mann-Whitney's U-test. pDAO, plasma diamine oxidase; NS, Not statistically significant; yr, year; m, month; av., average. 
TABLE 2.

Influence of nutritional therapy on plasma diamine oxidase activity $(n=14)$

\begin{tabular}{lcccc}
\hline \multirow{2}{*}{ Treatment } & $\begin{array}{c}\text { pDAO activity } \\
\text { (units/l) }\end{array}$ & vs. TPN & vs. TPN \& EN & vs. EN \\
\hline TPN & $4.73 \pm 1.02$ & - & NS & $<.0001$ \\
TPN \& EN & $5.46 \pm 1.48$ & NS & - & NS \\
EN & $6.84 \pm 1.18$ & $<.0001$ & NS & - \\
EN with SDF & $7.62 \pm 0.67$ & .0002 & .0075 & NS \\
PO & $8.82 \pm 1.26$ & $<.0001$ & .0003 & .0107 \\
\hline
\end{tabular}

pDAO activity is expressed as the mean \pm SD. Statistical analysis was performed using the Wilcoxon matched pair method. EN with SDF vs. PO: NS. pDAO, plasma diamine oxidase; TPN, total parenteral nutrition; EN, enteral nutrition; SDF, soluble dietary fiber $(0.5 \mathrm{~g} / \mathrm{kg} / \mathrm{day})$; PO, per oral nutrition; NS, not statistically significant.

TABLE 3.

Influence of chemotherapy on pDAO activity ( $n=9)$

Neuroblastoma stage II

\begin{tabular}{cccccc}
\hline & \multicolumn{2}{c}{ Cyclophosphamide $\left(300 \mathrm{mg} / \mathrm{m}^{2}\right)$} & & \multicolumn{2}{c}{ Vincristine $\left(1.5 \mathrm{mg} / \mathrm{m}^{2}\right)$} \\
\cline { 1 - 2 } \cline { 5 - 6 } & $\begin{array}{c}\text { pDAO activity } \\
\text { (units/l) }\end{array}$ & $P$ Value (vs. pre) & & $\begin{array}{c}\text { pDAO activity } \\
\text { (units/l) }\end{array}$ & $P$ Value (vs. pre) \\
\hline Pre & $6.76 \pm 1.52$ & - & & $7.62 \pm 2.08$ & - \\
1 & $1.96 \pm 0.57$ & .0431 & & $6.23 \pm 1.53$ & NS \\
2 & $2.24 \pm 1.18$ & NS & & $5.78 \pm 1.08$ & NS \\
3 & $3.46 \pm 1.36$ & .0431 & & $5.88 \pm 1.60$ & NS \\
4 & $2.89 \pm 2.22$ & .0277 & & $5.24 \pm 2.33$ & NS \\
5 & $3.50 \pm 2.87$ & NS & & $6.02 \pm 2.10$ & NS \\
6 & $4.69 \pm 3.14$ & NS & & $6.12 \pm 2.47$ & NS \\
7 & $7.93 \pm 2.37$ & NS & & $6.12 \pm 1.52$ & NS
\end{tabular}

pDAO activity is expressed as the mean \pm SD. Statistical analysis was performed using the Wilcoxon matched pair method. pDAO, plasma diamine oxidase; NS, not statistically significant.

TABLE 4.

Influence of chemotherapy on pDAO activity $(n=19)$

\begin{tabular}{|c|c|c|c|c|}
\hline & \multicolumn{2}{|c|}{$\begin{array}{c}\text { Neuroblastoma stage IVA }(\mathrm{n}=10) \\
\text { Cyclophosphamide }\left(900-1200 \mathrm{mg} / \mathrm{m}^{2}\right) \\
\text { with preparation using SDF }(1 \mathrm{~g} / \mathrm{kg} / \text { day })\end{array}$} & \multicolumn{2}{|c|}{$\begin{array}{l}\text { Neuroblastoma stage II }(\mathrm{n}=9) \\
\text { Cyclophosphamide }\left(300 \mathrm{mg} / \mathrm{m}^{2}\right) \\
\text { without preparation }\end{array}$} \\
\hline & $\begin{array}{l}\text { pDAO activity } \\
\quad \text { (units/l) }\end{array}$ & $\begin{array}{c}P \text { Value } \\
\text { (vs. pre/1 day) }\end{array}$ & $\begin{array}{l}\text { pDAO activity } \\
\text { (units/l) }\end{array}$ & $\begin{array}{l}P \text { Value } \\
\text { (vs. pre) }\end{array}$ \\
\hline Pre & $4.95 \pm 0.54$ & - & $6.76 \pm 1.52$ & - \\
\hline 1 & $4.43 \pm 0.51$ & $\mathrm{NS} /-$ & $1.96 \pm 0.57$ & .0431 \\
\hline 3 & $5.21 \pm 0.94$ & NS/.0277 & $3.46 \pm 1.36$ & .0431 \\
\hline 5 & $5.49 \pm 0.16$ & $\mathrm{NS} / .0431$ & $3.50 \pm 2.87$ & NS \\
\hline 7 & $5.06 \pm 0.38$ & NS/NS & $7.93 \pm 2.37$ & NS \\
\hline 14 & $5.18 \pm 0.45$ & NS/.0464 & $7.05 \pm 1.86$ & NS \\
\hline
\end{tabular}

pDAO activity is expressed as the mean \pm SD. Statistical analysis was performed using the Wilcoxon matched pair method. pDAO, plasma diamine oxidase; SDF, soluble dietary fiber; NS, not statistically significant. 
EN management period $(\mathrm{p}=.0107)$.

\section{Influence of chemotherapy on pDAO activity (Table 3 and 4)}

In 9 patients with neuroblastoma Stage II, the pDAO activity decreased significantly one day after CPM administration $(6.76 \pm 1.52 \rightarrow 1.96 \pm 0.57$ units $/ \mathrm{L}$; $\mathrm{p}=.0431$ ) and was suppressed significantly up to day 4 after CPM administration $(2.89 \pm 2.22$ units/L; $\mathrm{p}=.0277$ ). Gastrointestinal symptoms (nausea, anorexia and mild abdominal distension, diarrhea and so on) appeared from day 3 after CPM administration and continued for a few days. On the other hand, in the VCR administration period, pDAO did not show any significant changes and no symptoms were observed. Moreover, pDAO activity decreased slightly one day after CPM administration in 10 patients with neuroblastoma Stage IVA who were administered soluble dietary fiber $(1 \mathrm{~g} / \mathrm{kg} /$ day $)(4.95$ $\pm 0.54 \rightarrow 4.43 \pm 0.51$ units/L; not statistically significant), then increased at 3 days after treatment (5.21士 0.94 units/L; $\mathrm{p}=.0277$ ), and stayed at a high value thereafter. Vomiting and diarrhea were not observed during chemotherapy but anorexia appeared from 5 days after CPM administration for a few days.

\section{DISCUSSION}

DAO, along with ODC, shows a high activity in upper intestinal villi and controls the proliferation of the intestinal mucosal epithelium by regulating polyamine metabolism. DAO suppresses while ODC enhances putrescine concentration to control polyamine levels, hence these activities play important roles in proliferation of the intestinal mucosal epithelium [2]. Luk et al. reported that pDAO activity rose in parallel with intestinal DAO levels with age [5] and progressively decreased with increasing length of intestinal mucosal injury in adult rat [6]. Rokkas also reported that in adult human subjects, pDAO activity (after administration of heparin) was linearly related to jejunal mucosal DAO activity [12]. It was suggested therefore that the measurement of pDAO activity might be an objective means of evaluating intestinal functions that are difficult to evaluate clinically. However, this hypothesis has not been thoroughly verified under various conditions. In particular, only a few studies have reported pDAO activity in pediatric patients [7-9]. In an experiment on rats, Luk et al. [5」 reported that the DAO activity in intestinal tissue increased in the course of postnatal growth and development, reached a peak at
22 days old, and then remained at normal adult levels, and that plasma DAO activity varied in parallel with intestinal DAO activity. In clinical studies, a significant decrease of DAO activity was reported, but only in patients with celiac disease associated with severe atrophy of the intestinal mucosa $[8,9]$. We have reported with regard to the influence of liver dysfunction that pDAO activity increased in postoperative patients with biliary atresia (23 cases; $2 \mathrm{~m}-14 \mathrm{yrs} 1 \mathrm{~m}$, av. 6 yrs $8 \mathrm{~m}$ ) possibly due to insufficiency of its inactivation in the liver [10]. In the present study, we first determined the normal values of pDAO activity in each of the age groups of healthy children without any organic abnormalities, and then clinically examined the influences of several intestinal stresses (nutritional management, dietary fiber, and cyclophosphamide) on pDAO activity to clarify whether pDAO activity was influenced by intestinal stress and could serve as a useful index of the integrity and maturity of intestinal mucosal epithelium in children. The results showed that pDAO activity increased up to the age of three and then gradually decreased to become analogous to adult values. We suggest that the increase of pDAO activity up to the end of this age group was mainly attributable to the increase in absorptive area due to the rapid proliferation of intestinal epithelial cells during growth in childhood. These results are consistent with the results of the animal experiments by Luk et al. [5].

Next, we examined the influence of nutritional management on pDAO activity. Plasma DAO activity increased in the course of nutritional management from fasting TPN management, transition from TPN to EN management, EN maintenance period, soluble dietary fiber added EN management, to oral feeding. Significant recovery of pDAO activity was noted in EN management or later as compared with fasting TPN management, suggesting the recovery of intestinal tract integrity. Soluble dietary fiber administered in the EN maintenance period was indigestible and highly fermentative, was selectively utilized by Bifidobacterium and Lactobacillus to be degraded into short chain fatty acids, and was considered to be useful for improving intestinal bacterial flora and maintaining intestinal tract integrity [13-15]. Because pDAO activity during administration of soluble dietary fiber showed a significant increase in comparison with the dietary fiber non-administered period (transition from TPN to EN management), and was nearly equal to the value in the oral feeding period, it is possible that intestinal integrity could be 
restored by indigestible and highly fermentative dietary fibers after the atrophy of intestinal mucosa caused by fasting due to adhesive ileus. The above findings show that pDAO activity can be a useful index in nutritional management.

Abdominal symptoms including diarrhea are common gastrointestinal complications, and are caused by intestinal mucosal dysfunction due to anticancer drugs. The significant correlation between the severity of intestinal mucosal dysfunction due to anticancer drugs and pDAO activity has already been reported in adult patients [16,17]. Intestinal mucosal dysfunction by CPM is also critical in solid tumors of childhood patients, thus the influence of CPM on the small intestine was examined by measuring changes of pDAO activity in neuroblastoma patients. It is said that the effect of CPM on the immune system of intestinal mucosa is to suppress $\mathrm{CD}^{+} \mathrm{T}$ cells in the intestinal epithelium. This suppression is said to produce mucosal dysfunction by disturbing the immune system balance of the intestinal mucosa, and by causing the enhancement of cytokine secretion from the lamina propria mucosa, the decrease of $\operatorname{IgA}$ secretion, as well as the enhancement of cytotoxic Tcell activity [18]. The examination of the influence of chemotherapy in 9 patients with neuroblastoma Stage II revealed that even a relatively low dose of CPM $\left(300 \mathrm{mg} / \mathrm{m}^{2}\right)$ significantly decreased pDAO activity one day after administration and that this decreased level of activity was maintained thereafter. Gastrointestinal symptoms appeared from 3 days after CPM administration. On the other hand, no significant change of pDAO activity was noted during VCR administration, so it was considered that VCR had no influence on the intestine. Consequently, intestinal mucosal damage was considered likely to be caused by CPM, therefore measurement of $\mathrm{pDAO}$ activity may be useful for an early diagnosis of intestinal mucosal damage. In the advanced Stage IVA cases, pDAO activity fell slightly 1 day after administration, though it rose after 3 days and stayed at a high value thereafter. Partially hydrolyzed guar gum (a water-soluble dietary fiber) was given from 10 days before chemotherapy to prepare the patients in this series. Despite CPM doses 2-4 times higher than those in the Stage II group, pDAO activity did not decrease significantly, rather it stayed at a high value. Thus partially hydrolyzed guar gum can prevent intestinal mucosal damage caused by CPM and is useful for maintaining intestinal integrity.

At present, glutamine is given from 10 days before to 10 days after chemotherapy in preparation for multidrug therapies in advanced cases, and this was shown to improve gastrointestinal symptoms and inflammations such as fever. A study has described how glutamine can prevent the intestinal mucosal damage caused by chemotherapy [19]. These results are attributable to the effects of glutamine in maintaining intestinal mucosa integrity and improving the immune system [20,21]. Plasma DAO activity under glutamine administration will be the topic of a future report by us.

In conclusion, plasma DAO activity was greatly influenced by nutritional management and administration of dietary fiber and/or cyclophosphamide. Plasma DAO activity may be a sensitive marker of intestinal function in children.

\section{REFERENCES}

1. Baylin SB, Stevens SA, and Shakir KM. Association of diamine oxidase and ornithine decarboxylase with maturing cells in rapidly proliferating epithelium. Biochim Biophys Acta 1978; 541:415-419.

2. Mennigen R, Bieganski T, Elbers A, and Kusche J. The histamine-diamine oxidase system and mucosal proliferation under the influence of aminoguanidine and seventy percent resection of the rat small intestine. Agents Actions 1989; 27:221-223.

3. Shakir KM, Margolis S, and Baylin SB. Localization of histaminase (diamine oxidase) in rat small intestinal mucosa; site of release by heparin. Biochem Pharmacol 1977; 26:2343-2347.

4. D’Agostino L, Ciacci C, Capuano G, Daniele B, D' Argenio $\mathrm{G}$ et al. Metabolic fate of plasma diamine oxidase: Evidence of isolated and perfused rat liver uptake. Digestion 1986; 34:243-250.

5. Luk GD, Bayless TM, and Baylin SB. Diamine Oxidase (Histaminase) -A circulating marker for rat intestinal mucosal maturation and integrity. J Clin Invest 1980; 66:66-70.

6. Luk GD, Bayless TM, and Baylin SB. Plasma postheparin diamine oxidase. Sensitive Provocative test for quantitating length of acute intestinal mucosal injury in the rat. J Clin Invest 1983; 71:1308-1315.

7. Forget P, Grandfils C, and Van Cutsem JL G. Diamine oxidase and disaccharidase activities in small intestinal biopsies of children. Pediatr Res 1984; 18:647-649.

8. Forget P, Grandfils C, Van Cutsem JL, and Dandrifosse G. Diamine oxidase in serum and small intestinal biopsy tissue in childhood celiac disease. J Pediatr Gastroenterol Nutr 1986; 5:379-383.

9. Toporowska-Kowalska E, Wasowska-Krolikowska K, and Bodalski J. Diamine oxidase plasma activity and jejunal mucosa integrity in children with protracted diarrhoea. Rocz Akad Med Bialymst 1995; 40:499-503.

10. Tanaka Y, Mizote H, and Akiyoshi K. The clinical significance of plasma diamine oxidase (DAO) activity in pediatric surgery. Jpn J Surg Metab Nutr 1998; 32:61-66. 
11. Takagi K, Nakao M, and Ogura Y. Sensitive colorimetric assay of serum diamine oxidase. Clin Chim Acta 1994; 226:67-75.

12. Rokkas T, Vaja S, and Murphy GM. Postheparin plasma diamine oxidase in health and intestinal disease. Gastroenterology 1990; 98:1493-1501.

13. Okubo T, Ishihara N, and Takahashi H. Effect of partially hydrolyzed guar gum intake on human intestinal microflora and its metabolism. Biosci Biotech Biochem 1994; 58:1364-1367.

14 Alam NH, Meier R, and Schneider H. Partially hydrolyzed guar gum-supplemented oral rehydration solution in the treatment of acute diarrhea in children. $\mathbf{J}$ Pediatr Gastroenterol Nutr 2000; 31:503-507.

15. Spapen H, Diltoer M, and Van Malderen C. Soluble fiber reduces the incidence of diarrhea in septic patients receiving total enteral nutrition: a prospective, doubleblind, randomized, and controlled trial. Clin Nutr 2001; 20:301-305.

16. Imamura I, Shibayama H, and Minaguchi H. New noninvasive evaluation of anti-tumor agent: plasma diamine oxidase activity. Jpn J Clin Pharmacol Ther 1988; 19:161-164.

17. Tsujikawa $\mathrm{T}$, Uda $\mathrm{K}$, and Ihara $\mathrm{T}$. Changes in serum diamine oxidase activity during chemotherapy in patients with hematological malignancies. Cancer Lett 1999; 147:195-198.

18. Yamashiro Y, Ohtsuka Y, and Yabuta K. The regulation of intestinal Hypersensitivity reactions to ovalalbumin by $\omega-3$ fatty acid enriched diet. Studies of IEL and LPL in mucosal damage. Acta Paediatrica Japonica 1994; 36:550-556.

19. Ford C, James Whitlock JA, and Pietsch JB. Glutaminesupplemented tube feedings versus total parenteral nutrition in children receiving intensive chemotherapy. $J$ Pediatr Oncol Nurs 1997; 14:68-72.

20. Fox AD, Kripke SA, and De paula J. Effect of a glutamine-supplemented enteral diet on methotrexate-induced enterocolitis. J Parenter Enteral Nutr 1988; 12:325-331.

21. Horvath K, Jami M, and Hill ID. Isocaloric glutaminefree diet and the morphology and function of rat small intestine. J Parenter Enteral Nutr 1996; 20:128-134. 